\title{
Notes on behavioral economics and labor market policy
}

Linda Babcock', William J Congdon², Lawrence F Katz ${ }^{3^{*}}$ and Sendhil Mullainathan ${ }^{4}$

\author{
* Correspondence: Ikatz@harvard. \\ edu \\ ${ }^{3}$ Department of Economics, Harvard \\ University, Cambridge, MA 02138, \\ USA \\ Full list of author information is \\ available at the end of the article
}

\begin{abstract}
Labor market policies succeed or fail at least in part depending on how well they reflect or account for behavioral responses. Insights from behavioral economics, which allow for realistic deviations from standard economic assumptions about behavior, have consequences for the design and functioning of labor market policies. We review key implications of behavioral economics related to procrastination, difficulties in dealing with complexity, and potentially biased labor market expectations for the design of selected labor market policies including unemployment compensation, employment services and job search assistance, and job training.
\end{abstract}

Keywords: Behavioral economics, Unemployment insurance, Job training, Job search JEL: D03, D04, J08, J24, J64, J65

\section{Background and motivation}

The Great Recession of 2007 to 2009 and its aftermath have been a trying period for American workers. The U.S. unemployment rate reached double digits in late 2009 for the first time in over a quarter of a century and has remained over 8 percent through mid-2012. Real compensation growth has all but stalled. The human costs of labor market turbulence have rarely been clearer, and the value of public policies, such as unemployment insurance and job training programs, that assist workers in managing that turbulence, gaining new skills, and navigating the labor market have rarely been more apparent. Similar problems of persistent joblessness have been apparent in most major economies in recent years.

Even in the best of times, the United States' labor market is a dynamic and turbulent one with high rates of turnover (over five million separations and five million new hires in a typical month in normal times) but substantial frictions as well. As a result, labor market programs and regulations are key components of economic policy. Such policies help support the unemployed, provide education and training opportunities, and ensure the fairness, safety, and accessibility of the workplace. The challenge for policymakers in the United States and elsewhere is to design such policies so that they meet these goals as effectively and as efficiently as possible.

Labor market policies succeed in meeting their objectives, however, only to the extent that they accurately account for how individuals actually make decisions about work and leisure, job search, and education and training. To a substantial extent such

(C) 2012 Babcock et al.; licensee Springer. This is an Open Access article distributed under the terms of the Creative Commons Attribution License (http://creativecommons.org/licenses/by/2.0), which permits unrestricted use, distribution, and reproduction in any medium, provided the original work is properly cited. 
policies are built around standard economic assumptions of behavior that individuals are perfectly rational, time consistent, and entirely self-interested. The design of unemployment insurance with job search requirements intended to minimize distortions to incentives to return to work, the use of complicated eligibility criteria and administrative hassle factors to discourage social program participation except for the presumed most needy, and the shift to vouchers for training services have all been justified by these assumptions.

However, recent research at the intersection of psychology and economics-behavioral economics-is changing our understating of how individuals choose and act, and with it, some of our conclusions for policy design (Rabin 1998; Thaler and Sunstein 2008; Congdon, Kling, and Mullainathan 2011). Behavioral economics stresses empirical findings of behavior that are partially at odds with standard economic assumptions. The key empirical findings from field research in behavioral economics imply that individuals can make systematic errors or be put off by complexity, that they procrastinate, and that they hold non-standard preferences and non-standard beliefs (DellaVigna 2009). To the extent that these behavioral tendencies operate in labor market contexts, they may change both our understanding of the challenges that policy design must meet, as well as the opportunities and design tools available to policymakers.

In these notes, we briefly review selected topics in labor market policy through the lens of behavioral economics. We identify aspects of U.S. policy design that appear at odds with behavioral findings, as well as unrealized policy opportunities those findings suggest. The results of this review are prescriptions for policy design and innovation that reflect a synthesis of traditional and behavioral economic insights. We consider the implications of behavioral findings in three areas: unemployment insurance, job search assistance, and job training. Although we focus on the specifics of U.S. labor market policies, the lessons we draw potentially have broader applicability.

Some of the implications of behavioral economics for policy are overlooked in traditional formal economic analysis but reflect what might best be called "common sense" and are similar to the critiques and prescriptions of many long-time policy practitioners and analysts. These include recommendations to minimize the fragmentation and complexity of job training, employment, and social welfare programs. The behavioral approach also reinterprets traditional labor market policy proposals by taking into account loss aversion and potentially biased wage expectations, particularly relevant considerations in the case for and the design of wage-loss insurance policies. Behavioral findings from other domains generate new insights critical to the choice architecture and choice platforms for helping unemployed and disadvantaged workers navigate training and education options (Thaler and Sunstein 2008).

\section{Unemployment compensation}

Providing income support for the unemployed while encouraging their speedy return to work is a primary goal for labor policy. The ability of individuals (and even of many extended families) to self-insure, to smooth income and consumption out of savings and transfers from relatives and friends, is limited in the face of job losses and potentially extended spells of unemployment. Furthermore, private markets may fail to provide adequate mechanisms, such as loans, because of asymmetries of information. Our 
main policy instrument to maintain the consumption of job losers as they seek to gain reemployment is unemployment insurance (UI).

From the standard economic viewpoint, the main design challenge for UI is moral hazard. UI policies must balance the provision of liquidity and support for consumption smoothing during unemployment against the tendency of such benefits to distort incentives to search for and take new employment (Baily 1978; Chetty 2008). Increases in the generosity of benefits, either through increases in benefit levels or the duration of benefits, appear to lengthen the unemployment spells of unemployment insurance recipients (Meyer 1990; Katz and Meyer 1990).

In the United States, UI is a program administered jointly by the federal government and the states that replaces a substantial fraction of a qualified individual's lost wages when she becomes unemployed (through no fault of her own) and while she looks for new work. Ordinarily benefits can be collected for a maximum of six months (26 weeks), although this limit is often relaxed during national economic downturns by Congress through discretionary federal UI extensions. Longer potential benefit durations (extended benefits) can also be triggered at the state level in response to statespecific adverse economic shocks. The maximum duration of unemployment benefits in the highest unemployment states was extended by the U.S. Congress to 99 weeks in the depths of the Great Recession through the American Recovery and Reinvestment Act in 2009. Various reauthorizations kept the 99 week maximum through early 2012. Related programs and variants include wage-loss insurance, personal reemployment accounts, reemployment bonuses, and subsidies to continue health insurance coverage following job loss.

U.S. unemployment benefits are contingent on active job search efforts (job search requirements) and benefits are strictly time limited in part to address the potential for moral hazard. Time-limited UI benefits can be interpreted as a crude version of the key implication of the Shavell and Weiss (1979) standard model of optimal unemployment insurance that benefits should decrease with duration of unemployment to provide appropriate search incentives. There has been some experimentation with the terms of unemployment compensation to further promote reemployment including the use of reemployment bonuses, variation in the intensity of monitoring job search, and the provision of job search assistance and self-employment assistance. But such efforts have to date generated only mixed results (Meyer 1995; Black et al. 2003).

\subsection{The behavioral economics of unemployment compensation}

Behavioral economics suggests several other psychological barriers to job search distinct from moral hazard. One set of barriers arises from the way in which individuals form expectations about wages and evaluate their employment prospects. Behavioral economics introduces the possibility that individuals will form such expectations with error or systematic bias, and are likely to be "loss averse" in evaluating job offers asymmetrically around those expectations (Kahneman and Tversky 1979). These effects may operate to slow their return to work and reinforce the moral hazard problems in unemployment compensation schemes of unemployed workers not putting in adequate search efforts and setting inefficiently high reservation wages in response to more generous benefits while unemployed. 
Another set of behavioral barriers to reemployment arise from the tendency of individuals to have imperfect self-control, such as expressed by time inconsistent preferences (Laibson 1997). As a result, individuals may procrastinate in their job search efforts even when such delay is against their own, long-run self-interest. These considerations complicate the moral hazard problem by creating potential conflicts between an unemployed individual's current and future selves as well as the standard conflict between the benefits of the recipient and the program operators. These factors generate a situation where stronger work and job search requirements that appear overly paternalistic in the usual model of homo economics may actually benefit the program participants themselves by helping them overcome self-control problems.

These behavioral factors change the central challenge associated with providing efficient unemployment insurance in at least two ways. First, in addition to balancing the insurance value of unemployment compensation against the social costs of any associated moral hazard, optimal unemployment insurance with behavioral agents must also consider the welfare implications of decision-making errors or biases (Spinnewijn 2010). Second, incentives in UI programs may need to account for behavioral tendencies, such as loss aversion or time inconsistency, to operate effectively.

\subsection{Reform proposal: Implement some form of wage loss insurance}

Individuals return to work when they get a job offer paying above their reservation wage. In standard theory, individuals are assumed to form reservation wages in a rational manner incorporating unbiased expectations of market wages and an accurate assessment of the market value of their skills. As a result of the behavioral tendencies outlined above, however, unemployed individuals may be reluctant to entertain and slow to accept even objectively reasonable wage offers. The current structure of unemployment insurance and related programs does not address this tendency, but the efficiency of these programs may suffer because of it. Individuals holding out for offers that will not come remain on the unemployment insurance roles for inefficiently long periods. Of particular concern is the possibility that individuals will set their reservation wage at the level of wages they have received on past jobs, whether or not this is realistic given prevailing labor market conditions (Feldstein and Poterba 1984; Ball and Moffitt 2001; Hogan 2004). Moreover, individuals might be loss averse in the sense of having preferences that are asymmetric around their previous wage with a particularly large psychological cost to taking a job paying below their past earnings. The combined effect might be to lead individuals to be irrationally reluctant to accept job offers below their preseparation wage, to be unwilling to relocate to areas with greater labor market opportunities, and to search mainly for jobs like their previous one or to pass up reasonable opportunities while waiting for their old job (or one just like it) to return. This phenomenon has been called "retrospective wait unemployment" and is particularly important for longtenured workers displaced from high-wage sectors in decline such as autos and steel (Summers 1986; Balls et al. 1991). It is reinforced by the social status and personal identities of many workers being strongly tied to their previous jobs.

A policy to address these issues and supplement UI for likely permanent job losers is wage-loss insurance (also called wage insurance) which (at least temporarily) subsidizes worker earnings upon reemployment when the wage they receive on their new job is 
less than that of their old job. Economists have noted several advantages to wage-loss insurance, such as the ability to better target benefits to those workers who face the most severe consequences of job loss (Kletzer and Litan 2001; Kling 2006). Although behavioral economics does not change that logic, it does identify additional advantages to wage-loss insurance. By manipulating the realized value of wages (especially if the wage-loss insurance payments show up directly in one's regular paycheck) and making job offers more attractive, it averts to some degree the impacts of biased wage expectations and mitigates the effects of loss aversion. In the longer run, it may smooth the painful but sometimes necessary process of psychological adjustment to lower-wage employment. Consideration of wage-loss insurance proposals should weigh these behavioral advantages, and any demonstration projects or evaluations of wage-loss insurance, such as that currently being conducted as part of the U.S. Trade Adjustment Assistance program, should take care to test for the possible importance of these behavioral dimensions.

In addition to providing further justifications for existing wage-loss proposals, behavioral factors also generate specific design recommendations. For example, the effects of biased wage expectations or reference dependence with respect to those expectations call into question the likely efficacy of partial wage insurance at speeding up returns to work for displaced workers. These behavioral concerns are consistent with the limited impacts on reemployment rates and job search efforts found in a Canadian demonstration project testing partial-replacement wage insurance for displaced workers (Bloom et al. 2001). An alternative might be to structure wage-insurance as full or nearly full insurance upon reemployment, and declining over time possibly in a manner linked to typical wage growth patterns on new jobs. Of course, the benefits of such a redesign in mitigating the effects of biased wage expectations and loss aversion must be weighed against the possible costs it might impose on targeting and allocative efficiency.

\subsection{Research agenda: Experiment with incentive schemes in unemployment compensation} Limits to self-control represent another likely behavioral barrier to creating incentives to return to work in unemployment compensation programs. A key design challenge for UI is to provide temporary income support while maintaining the incentives of the unemployed to search for and return to work. Procrastination and other expressions of bounded self-control complicate that problem substantially. Findings that the unemployed spend only a modest amount of time per week searching for work are consistent with such procrastination (Krueger and Mueller 2010). Much suggestive evidence indicates that many job seekers may have time inconsistent preferences and tendencies to procrastinate in job search efforts (DellaVigna and Paserman 2005; Paserman 2008). The effects of benefit design on search intensity are thus not simply a product of financial payments from continued unemployment, but instead a more subtle interaction between benefits, incentives, and willpower. Particularly problematic for policy, these tendencies may serve to blunt the force of design features intended to align incentives. The result is that work incentives in programs like UI must address both moral hazard as well as procrastination.

That the work incentive problem in UI may take on this different character when allowing for behavioral tendencies such as procrastination suggests an agenda of experimentation with the structure of unemployment benefits. Demonstration projects 
experimenting with changes to the UI compensation structure have a long history. Past efforts have included reemployment bonus experiments and a demonstration of Personal Reemployment Accounts (PRAs) (Meyer 1995; Kirby et al. 2008). However, evaluations of these efforts have yielded somewhat mixed results. This may be in part due to the failure of these projects to consider factors such as bounded self-control. For example, reemployment bonuses, contingent as they are on possibly distant outcomes such as gaining reemployment and holding the new job for at least several months, may provide little in the way of an effective incentive to individuals who choose levels of search effort day to day.

Behavioral economics suggests new directions for experiments with alternative incentive schemes in unemployment insurance and related programs that recognize the role of self-control in returning to work. One direction that appears promising would be to offer small, immediate, and high frequency reminders and incentives to search. So instead of tying rewards and penalties to large, distant, low frequency objectives, such as regaining employment for a significant duration of time, unemployment insurance might tie rewards and penalties to smaller, higher frequency objectives, such as making a specific number of active employer contacts in a week. Other candidates for testing are incentives that trigger avoidance of anticipated regret, and rewards with lottery-like characteristics, which have been effective in the presence of self-control problems in other contexts (Volpp et al. 2008). Another direction for experimentation entirely would be to test the possibility of overcoming imperfect self-control by creating a principal-agent relationship in which placement agents receive the bonuses. Key issues that will need to be addressed in the design of such policies using employment intermediaries are limiting cream skimming incentives (which arise if the intermediaries can "choose" their clients) and making sure that payments to intermediaries are tied to longer-term employment and earnings outcomes rather than only to short-term reemployment rates and use of services (Autor and Houseman 2010; Heinrich and Choi 2007).

\section{Employment services and job search assistance}

Labor market policies can play an important role in assisting individuals with the job search process. Basic employment services, such as the coordination of job listings by the public employment services in many nations, seek to provide a public good both to workers and to employers. More active job search assistance policies essentially provide a form of human capital to workers in improving their job search skills and labor market information. The overarching goal of such programs is to help individuals return to work quickly and to improve the quality of matches between workers and jobs.

In the United States a portfolio of interconnected programs supports this goal, and includes informational services as well as active job search assistance. Public employment services - The Employment Service (ES) - provide placement assistance to both workers and employers, maintains labor exchange listings, and performs outreach to employers. Services provided under the U.S. Workforce Investment Act (WIA) include counseling and assistance for job seekers. Workers obtain access to these services through multiple points of entry, one of the most important of which are worker profiling referrals from the UI system. These services are supported by employment data and projections complied by the U.S. Department of Labor and its state partners. 
The evidence from a wide range of evaluations suggests that services of this nature are typically effective at helping individuals to obtain employment more rapidly, and, largely as a result, can raise earnings at least in the short-run (LaLonde 1995; O'Leary 2004). Positive impacts have been found for most types of these services, including employment services and job search assistance, and for most populations who use them, including those on UI as well as the economically disadvantaged including participants in welfare-to-work programs. Because such services are relatively inexpensive to provide on a per participant basis, they are usually found to be cost effective.

\subsection{The behavioral economics of employment services and job search assistance}

Behavioral tendencies may help to explain the consistent effectiveness of employment services and job search assistance. The behavioral barriers to search described abovebiases and error in setting wage expectations, procrastination in searching for work, and so on-suggest a role for this assistance. To the extent that formal assistance can ameliorate or overcome these problems, these policies will speed reemployment.

In addition, there are behavioral barriers to job search that arise simply due to the fact that it is an intrinsically difficult problem. Optimal job search requires considering information about job market conditions and how they match with personal characteristics in a way that is likely to be difficult for imperfectly rational individuals. Behavioral economics stresses that individuals are limited in the attention and the computational capacity they can bring to multifaceted and complex problems (Tversky and Shafir 1992; Tversky and Kahneman 1974; Iyengar and Lepper 2000). As a result, the speed and quality of employment matches may both suffer due to the tendency of fallible individuals to manage the complex tasks of job search. And programs that assist individuals with managing that complexity can help them obtain work.

These behavioral dimensions to job search change our understanding of the challenges faced by employment services and job search assistance programs. The behavioral perspective implies employment programs need to operate directly on the aspects of individual decision-making that might lead to privately inefficient search and match their design to the biases they hope to correct. For example, it may be insufficient to simply make job market information available. Program effectiveness may be enhanced by actively seeking to debias expectations, ensure the understanding of labor market information, and provide incentives to combat procrastination in job search.

\subsection{Policy proposal: Simplify and expand employment services and job search assistance}

Searching for jobs may be more difficult for individuals than the standard model typically allows. Looking for work is, in the first place, a substantial information problem. Workers have to understand labor market conditions, have knowledge of openings and applications processes, possess an accurate understanding of their own skill level and how firms and markets might value those skills, and determine the quality of matches with employers. Moreover, searching for work requires willpower, which can be costly for individuals to draw upon. Workers may be tempted to procrastinate in their job search efforts in favor of other activities. Well-designed employment services and job search assistance programs have the potential to assist with both of these issues. 
One proposal that follows from a behavioral view of job search is that expanding access to employment services or job search assistance is likely to be worthwhile. Evidence suggests that individuals are bad at knowing that job search is effective, that is, that they underestimate the benefits of search (Spinnewijn 2010), which may result in individuals choosing a lower than optimal level of search. Policies might thus seek to promote enrollment in these activities beyond what individuals would choose on their own, for example, by increasing the instances in which individuals can be defaulted into such services, such as through worker profiling upon signing up for UI. Default required job search activities might help individuals to overcome any tendency to procrastinate search. Evidence that individuals can be encouraged to take jobs just by enrolling them in job search programs - that individuals are encouraged to take jobs either very early into such programs or before such programs even begin-is consistent with this hypothesis (Director and Englander 1998; Black et al. 2003). But one does also need to take into account the potential displacement (or spillover) effects of job search assistance for targeted groups of the unemployed on the outcomes of other job seekers for a full evaluation of the impacts of such policies (Crépon et al. 2012).

Another proposal is to simplify and streamline the experience of workers seeking employment services or job search assistance. Employment and job search assistance tools should be widely available and easy to use, both online and in public employment service offices (or in U.S. One-Stop Career Centers). These tools could gather information on an individual's background and interests, provide feedback on the education and employment opportunities pursued by others like them, list job openings they may be interested in, and provide information on the projected growth in occupations and in other local areas in an easily accessible manner.

In addition to simplifying the process of obtaining assistance, employment service activities should also present information on local labor market conditions and occupational projections with an eye to how it will be construed by recipients, not just what information it contains. For example, it is one thing to say that a certain sector is expanding or contracting but probably a different level of information transmission to convey what it means to be in that sector and incorporate this information into labor exchange systems. That is, policy should seek not only to improve the precision of information like occupational projections, but also the way in which that information is conveyed to individuals. Information should be simple and personalized.

\subsection{Research agenda: Study methods of presenting job search information}

Employment services and job search assistance face behavioral barriers to their effectiveness beyond the difficulties individuals may have with the complexity or the willpower requirements of job search. Most prominently, the systematic biases or reference dependence related to previous earnings that unemployed individuals may exhibit with respect to wage expectations can remain an impediment to seeking and accepting work. Job search assistance can potentially work to address the biases, frames, or other cognitive obstacles to employment because it represents an opportunity for policy to influence how individuals understand the possibilities before them in the job market. Behavioral economics suggests that the way in which job opportunities are framed can matter for how individuals respond to choices. This suggests a research agenda to experiment with 
modifications to the presentation of job search information beyond simplification. Policymakers can innovate in the way that employment services are presented to individuals.

One area for research and experimentation is the potential of using the presentation of information or counseling that can be part of job search assistance programs to debias wage expectations. There are good reasons to think that one behavioral barrier to job search and employment is that individuals may have biased wage expectations. Evidence from other contexts suggests that debasing of such beliefs is possible through carefully designed interventions (Babcock, Lowenstein, and Issacharoff 1997). This research suggests that having people question their own judgment by explicitly considering counterarguments to their own thinking can be effective. Job search assistance could potentially incorporate such an exercise with respect to wage expectations. There has been some comparative effectiveness type research on job search assistance, testing the relative success of differently structured job search assistance programs (Decker et al. 2000). Research into wage expectations debasing could follow a similar path.

There is also scope for research into other aspects of the presentation of employment services information or job search assistance. The presentation and context of this information can potentially invoke frames of loss or gain, emotions such as anger or sadness, different propensities toward risk taking, and so on. This framing can affect choices not by overcoming biases or behavioral tendencies but by working within their limits. One promising area of study involves manipulations to the way job search assistance is framed for participants. Framing consequences as losses instead of gains, for example, is known to affect behavior in other contexts (Rothman et al. 2006). This framing can also affect the willingness of participants to take risks, such as the risk of interviewing for or starting a new job. Framing might also be used to attempt to influence the reference points around which individuals judge alternatives and thereby impact attitudes toward job opportunities.

\section{Job training}

Another important set of labor market policies is concerned with providing access to opportunities to acquire and upgrade skills and earning power. Public support for job training can be viewed as a response to positive externalities to human capital acquisition or in helping individuals overcome capital market imperfections, much as with education investments more generally. Such policies can also serve to address distributional concerns, for example as part of the compensation and safety net that society provides to those dislocated by trade or technology. A primary operational challenge for job training policy is to deliver these benefits in a well-targeted and efficient manner.

The current centerpiece of U.S. public-sector job training program efforts is the Workforce Investment Act (WIA). WIA offers occupational skills training and on-thejob training programs to both dislocated and disadvantaged workers. Services are delivered through One-Stop Career Centers, and funds are provided in Individual Training Accounts (ITAs), which workers draw on to purchase training services from various providers, such as community colleges. Other major supports for job training include Pell Grants, which low-income workers can use to fund educational programs that lead to a certificate or degree, and the Lifetime Learning Credit, which is a nonrefundable tax credit available to offset educational expenses. 
Although the labor market returns to education in general are well established, programs that support job training for mid-career individuals have a mixed record of effectiveness (Greenberg, Michalopoulos, and Robins 2003). In part, this reflects the heterogeneity of both programs of this type as well as the populations they serve. Historical evidence suggests that some participants, in particular adult women, benefit consistently from job training, in the form of improved earnings, while others, including adult men, often do not. Benefits to specific training programs, where evident, are typically small in absolute terms and evidence about their persistence is scattered. A key caveat in interpreting this evidence is most of the evaluations cover training programs that are not intensive, are of short duration, and are not very different from the substitute education and training programs utilized by members of the control group. Some evidence shows that more intensive training treatments, such as completing courses leading to a certificate or degree at a community college, generate substantial improvements in earnings (Jacobson, LaLonde, and Sullivan 2005). The direct evidence on WIA training services is in the form of non-experimental work, and is inconclusive (Heinrich, Mueser, and Troske 2008; Hollenbeck et al. 2005).

\subsection{The behavioral economics of job training}

Behavioral economics suggests that the disappointing results of some job training programs may be due in part to a failure of such programs to respond accurately to the psychology of workers who could benefit from training. Results from behavioral economics suggest that the determination of whether and when to undertake job training, the selection of a field to be trained in as well as a provider, and the pursuit and completion of that training, represents an intrinsically challenging sequence of choices and actions for imperfectly rational individuals. As noted above, research shows that individuals often fail to choose "optimally" in such settings and can have difficulty exerting self-control in starting up and persisting in investment activities with distant payoffs. A successful workforce investment system is likely to be one that reduces complexity and the need for willpower from the perspective of workers, and relies less heavily on wellinformed, patient participants for its smooth operation and success.

The key differences implied by the presence of behavioral tendencies for job training policy are likely to be twofold. First, policy must contend with the fact that accessing and following through with training may be difficult for many individuals. This creates a challenge not only to serving the optimal number of beneficiaries, but also for efficiently targeting benefits. Standard economic models imply that hassle factors, stigmatizing application processes, and other costs to accessing programs may improve the targeting of programs by screening out those with low expected benefits and self-selecting into programs those individuals who rationally assess the benefits to be most valuable (Parsons 1991). But when there is heterogeneity in the extent to which individuals' behavior departs from standard economic assumptions, these hurdles to program entry and to eligibility certification and recertification may generate inefficient screening leaving the most vulnerable (who are the least able to navigate such processes) behind (Bertrand, Mullainathan, and Shafir 2004).

Second, imperfectly optimizing individuals create an additional layer of challenges for providing job training services through market-based mechanisms, a potentially efficient way to deliver such benefits for standard rational economic actors. But if individuals choose only 
imperfectly and are greatly swayed by defaults and packaging and framing of information, the resulting market pressures may produce behavior that strays further from optimal outcomes. Market mechanisms in this context should be designed to be robust to such imperfect decision making by beneficiaries.

\subsection{Policy proposal: Simplify job training services}

Existing U.S. job training programs are typically not focused on being easy to use from the participant's perspective. Past efforts to streamline services have mainly emphasized administrative efficiency, rather than the experience of the user. Programs remain somewhat fragmented and can be complicated to access and navigate. Moreover, in recent decades, U.S. job training policy has moved from publicly-provided job training services to a model of providing individuals access to funding to pursue their own choice of training opportunities in a marketplace of competing providers. Although this shift in focus has potential benefits, it also places a burden on workers that they may be ill equipped to manage and which may impair program effectiveness. This burden may impact participants differentially, raising the possibility that the very individuals who might benefit most from training may have the most difficulty in obtaining it.

One set of policy recommendations that follow from these observations is that it should be an explicit goal of WIA to provide job training services in a manner that is streamlined from the perspective of prospective users. Job training services in WIA should seek to minimize barriers to take-up. These programs should also take active steps to ensure that program requirements are not, in practice, most onerous for those individuals most in need. In addition, training programs provided through One-Stop Career Centers should emphasize reducing complexity and providing guidance to participants as priorities. One method for providing guidance would be to enhance the counseling services that accompany ITA receipt, although previous experimentation along these has not been promising (McConnell et al. 2006). Another approach would be to institute rules (such as developing appropriate default options) or tailor program parameters (such as ITA value) in such a way so as to better direct choice. A further option currently being tested is the integration within One-Stop Career Centers of both guidance on training and education options as well as help in accessing and understanding available financial work supports (e.g., the Earned Income Tax Credit and child care subsidies) and social assistance programs (e.g., food stamps) (Miller, Tessler, and van Dok 2009).

A similar set of recommendations also applies to job training services available outside of WIA. On the one hand, access to these services, such as Pell grants, should be simplified. Current proposals to simplify the form and application process for federal student aid are consistent with this goal (Dynarski and Scott-Clayton 2008). Likewise, the Lifetime Learning Credit could possibly be more effective if structured as a match. On the other hand, programs such as these should be integrated with WIA services to the greatest extent possible. For example, where not already the case, Pell recipients enrolled at a community college should receive services through the associated One-Stop Career Center. The One-Stop system is many ways the right model on which to build, but policy should reflect a renewed emphasis on the ease of use from the perspective of participants. Available qualitative evidence supports that idea that integrating services is likely to improve the participant experience (Barnow and King 2005). 
Finally, an emphasis on simplifying the user experience in job training recommends continued experimentation with job training policies that require less active decisionmaking on the part of participants. Examples include the support of employer-provided incumbent worker training, or of other demand-side programs that directly fund training services in high-wage and expanding industries.

\subsection{Research proposal: Experiment with choice platforms for job training advice}

A different model for ensuring that individuals qualifying for job training services receive effective guidance and assistance would be to experiment with creating a structured market for providers of counseling and advice. The current system of training assistance, both through ITAs under WIA and through funds available through student financial aid or tax credits, is built upon markets for training services in which providers such as community colleges and proprietary schools compete for training dollars. The idea behind this approach is that participants will apply competitive pressure on training providers to offer effective services. But the complexity of the choices involved limits the capacity of individuals to drive these markets toward such outcomes. In other contexts such as the prescription drug plan choices by the elderly under Medicare Part D and public school choice programs, behavioral economics research has found that a large number of complex choices hinders decision-making and that interventions providing personalized and transparent information on the most "relevant" choices can improve decision-making outcomes (Kling et al. 2012; Hastings and Weinstein 2008). Thus, there is some reason to believe that similar efforts could bear fruit with respect to job training.

Job training policy should experiment with the creation of new markets for job training advice in order to improve the capacity of individuals to make good choices about providers of job training services, and, ultimately, improve the operation of the market for job training services. Such an approach would operate by creating a market in which providers of counseling and advice competed to serve individuals. The key would be that the success or failure of those providing counseling and advice would be determined by objective measures of their performance.

Practical considerations for making such a proposal work would be paramount, and so experimentation is necessary. Competition could be structured so that firms doing well in providing advice and counseling according to workforce performance measures gain market share. Individuals registering for training would be referred to one of several providers of counseling. More effective providers will be given progressively more referrals, by reallocating the flow of beneficiaries over time, while ineffective providers will see their client base decrease. Considerable attention would need to be devoted to preventing selection of particular trainees by providers. Referrals could be assigned randomly, or on a rotational basis, to allow direct comparisons of the average performances of different providers (Bartik 1995). Finally, to avoid conflicts of interest, it would also be necessary that these intermediaries have no connection to the underlying service providers. A regulatory firewall could prohibit financial ties between providers and employers with whom individuals are placed, to solidify the counselors' role as honest brokers. It could be possible for government and 
private providers to operate in the same market, with each receiving fixed funding per person served.

Finally, note that any innovation of this nature would be dependent for its success on the WIA performance measurement system. There is a good deal of evidence that the existing system is inadequate to such a task, and there are a number of proposals for improvement (Jacobson 2009). These efforts would be complementary to efforts to build an effective choice platform for advice markets.

\section{Conclusion}

A review of the intersection of behavioral economics and current U.S. labor market policies suggest specific policy reforms and motivates demonstration and evaluation projects in areas where greater knowledge is needed. We have noted potential reforms and promising research projects in the domains of unemployment compensation, job search assistance, and job training. Although these are only a few selected applications, they demonstrate the promise of a behavioral approach to labor market policy. Realizing this promise more fully is an important goal for future research.

\section{Competing interests}

The IZA Journal of Labor Policy is committed to the IZA Guiding Principles of Research Integrity. The authors declare that they have observed these principles.

\section{Acknowledgments}

We are grateful to Jeffrey Kling for extensive discussions of these topics. We thank the anonymous referee, Juan Francisco Jimeno and Núria Rodríguez-Planas for helpful comments. Financial support was provided by the Alfred P. Sloan Foundation and the Russell Sage Foundation.

Responsible Editor: Juan Francisco Jimeno

\section{Author details}

${ }^{1} \mathrm{H}$. John Heinz III School of Public Policy and Management, Carnegie Mellon University, Pittsburgh, PA 15213, USA. ${ }^{2}$ Brookings Institution, 1775 Massachusetts Avenue, NW, Washington, DC 20036, USA. ${ }^{3}$ Department of Economics, Harvard University, Cambridge, MA 02138, USA. ${ }^{4}$ Department of Economics, Harvard University, Cambridge, MA 02138, USA.

Received: 24 July 2012 Accepted: 8 August 2012

Published: 9 October 2012

\section{References}

Autor DH, Houseman SN (2010) Do Temporary Jobs Improve Labor Market Outcomes for Low-Skilled Workers? Evidence from "Work First". Am Econ J Appl Econ 2:96-128

Babcock L, Lowenstein G, Issacharoff S (1997) Creating Convergence: Debiasing Biased Litigants. Law Soc Inq 22:913-925

Baily MN (1978) Some Aspects of Optimal Unemployment Insurance. J Public Econ 10:379-402

Ball L, Moffitt R (2001) Productivity Growth and the Phillips Curve. NBER working paper 8421. NBER, Cambridge, MA

Balls E, Katz LF, Summers LH (1991) Britain Divided: Hysteresis and the Regional Dimension of Britain's Unemployment Problem. Harvard University working paper, Cambridge, MA

Barnow B, King C (2005) The Workforce Investment Act in Eight States. Report to the Dept. of Labor. Rockefeller Institute of Government, Albany, NY

Bartik T (1995) Using Performance Indicators to Improve the Effectiveness of Welfare-to-Work Programs. Upjohn Institute Staff Working Paper, pp 95-36. W.E. Upjohn Institute for Employment Research, Kalamazoo, MI Bertrand M, Mullainathan S, Shafir E (2004) A Behavioral-Economics View of Poverty. Amer Econ Rev 94:419-423

Black DA, Smith JA, Berger MC, Noel BJ (2003) Is the Threat of Reemployment Services More Effective than the Services Themselves? Evidence from Random Assignment in the UI System. Amer Econ Rev 93:1313-1327

Bloom HS et al (2001) Testing a Financial Incentive to Promote Re-employment Among Displaced Workers: The Canadian Earnings Supplement Project (ESP). J Pol Anal Manag 20:505-523

Chetty R (2008) Moral Hazard vs. Liquidity in Optimal Unemployment Insurance. J Polit Econ 116:173-234

Congdon WJ, Kling JR, Mullainathan S (2011) Policy and Choice: Public Finance through the Lens of Behavioral Economics. Brookings, Washington

Crépon B, Duflo E, Gurgand M, Rathelot R, Zamora P (2012) Do Labor Market Policies Have Displacement Effects? Evidence from a Clustered Randomized Experiment, CREST working paper

Decker PT et al (2000) Assisting Unemployment Insurance Claimants: The Long-Term Impacts of the Job Search Assistance Demonstration. Mathematica Policy Research, report to the Dept. of Labor

DellaVigna S (2009) Psychology and Economics: Evidence from the Field. J Econ Lit 47:315-372 
DellaVigna S, Paserman MD (2005) Job Search and Impatience. J Labor Econ 23:527-588

Director S, Englander F (1998) Requiring Unemployment Insurance Recipients to Register with the Public Employment Service. J Risk Insur 55:245-258

Dynarski S, Scott-Clayton J (2008) Complexity and Targeting in Federal Student Aid: A Quantitative Analysis. In: Poterba JM (ed), 22nd edn Tax Policy and the Economy, pp 109-150. University of Chicago Press, Chicago

Greenberg D, Michalopoulos C, Robins P (2003) A Meta-Analysis of Government-Sponsored Training Programs. Ind Labor Relat Rev 57:31-53

Hastings J, Weinstein J (2008) Information, School Choice, and Academic Achievement: Evidence from Two Experiments. Q J Econ 123:1373-1414

Heinrich C, Choi Y (2007) Performance-Based Contracting in Social Welfare Programs. Amer Rev Public Adm 37:409-435

Heinrich C, Mueser P, Troske K (2008) Workforce Investment Act Non-Experimental Net Impact Evaluation. IMPAQ International, report to Dept. of Labor. IMPAQ International, Columbia, MD

Hogan V (2004) Wage Aspirations and Unemployment Persistence. J Monet Econ 51:1623-1643

Hollenbeck K et al (2005) Net Impact Estimates for Services Provided through the Workforce Investment Act. report to Dept. of Labor

Feldstein M, Poterba J (1984) Unemployment Insurance and Reservation Wages. J Public Econ 23:141-167

lyengar S, Lepper M (2000) When Choice is Demotivating: Can One Desire Too Much of a Good Thing? J Pers Soc Psychol 79:995-1006

Jacobson L (2009) Strengthening One-Stop Career Centers. Helping More Workers Find Jobs and Build Skills, Hamilton Project Discussion Paper, 2009-01. The Hamilton Project, Washington, DC

Jacobson L, LaLonde R, Sullivan D (2005) Estimating the Returns to Community College Schooling for Displaced Workers. J Econom 125:271-304

Kahneman D, Tversky A (1979) Prospect Theory: An Analysis of Decision under Risk. Econom 47:263-291

Katz LF, Meyer BD (1990) The Impact of the Potential Duration of Unemployment Benefits on the Duration of Unemployment. J Public Econ 41:45-72

Kirby G et al (2008) Responses to Personal Reemployment Accounts (PRAs). Findings from the Demonstration States. Mathematica Policy Research, report to U.S. Department of Labor. Mathematica Policy Research, Inc., Washington, DC

Kletzer L, Litan R (2001) A Prescription to Relieve Worker Anxiety. Brookings Institution Policy Brief 73. Brookings, Washington

Kling JR (2006) Fundamental Restructuring of Unemployment Insurance. Hamilton Project Discussion Paper, pp 2006-05. The Hamilton Project, Washington, DC

Kling JR, Mullainathan S, Shafir E, Vermeulen LC, Wrobel MV (2012) Comparison Friction: Experimental Evidence from Medicare Drug Plans. Q J Econ 127:199-235

Krueger A, Mueller A (2010) Job Search and Unemployment Insurance: New Evidence from Time Use Data. J Public Econ 94:298-307

Laibson D (1997) Golden Eggs and Hyperbolic Discounting. Q J Econ 112:443-477

LaLonde R (1995) The Promise of Public Sector-Sponsored Training Programs. J Econ Perspect 9:149-168

McConnell S et al (2006) Managing Customers' Training Choices: Findings from the Individual Training Account Experiment. Mathematica Policy Research, report to the Dept. of Labor. Mathematica Policy Research, Inc., Washington, DC

Meyer BD (1990) Unemployment Insurance and Unemployment Spells. Econom 58:757-782

Meyer BD (1995) Lessons from the U.S. Unemployment Insurance Experiments. J Econ Lit 33:91-131

Miller C, Tessler B, van Dok M (2009) Strategies to Help Low-Wage Workers Advance: Implementation and Early Impacts of the Work Advancement and Support Center (WASC) Demonstration. MDRC, New York

O'Leary C (2004) Evaluating the Effectiveness of Labor Exchange Services. In: Balducchi E, Eberts R, O'Leary C (eds) Labor Exchange Policy in the United States, pp 135-178. W.E. Upjohn Institute for Employment Research, Kalamazoo, M!

Parsons D (1991) Self-Screening in Targeted Public Transfer Programs. J Polit Econ 99:859-876

Paserman MD (2008) Job Search and Hyperbolic Discounting: Structural Estimation and Policy Evaluation. Econ J 118:1418-1452

Rabin M (1998) Psychology and Economics. J Econ Lit 36:11-46

Rothman AJ, Bartels RD, Wlaschin J, Salovey P (2006) The Strategic Use of Gain- and Loss-Framed Messages to Promote Healthy Behavior: How Theory Can Inform Practice. J Commun 56:S202-\$220

Shavell S, Weiss L (1979) The Optimal Payment of Unemployment Benefits over Time. J Polit Econ 87:1347-1362

Spinnewijn J (2010) Unemployed but Optimistic: Optimal Insurance Design with Biased Beliefs. LSE working paper, London

Summers LH (1986) Why is Unemployment So High at Full Employment? BPEA 2:339-382

Thaler RH, Sunstein CR (2008) Nudge. Yale University Press, New Haven, CT

Tversky A, Kahneman D (1974) Judgment under Uncertainty: Heuristics and Biases. Science 185:1124-1131

Tversky A, Shafir E (1992) Choice under Conflict: The Dynamics of Deferred Decision. Psych Sci 3:358-361

Volpp KG et al (2008) A Test of Financial Incentives to Improve Warfarin Adherence. BMC Health Serv Res 8:272

doi:10.1186/2193-9004-1-2

Cite this article as: Babcock et al: Notes on behavioral economics and labor market policy. IZA Journal of Labor Policy 2012 1:2. 